\title{
NOTA DE LOS EDITORES
}

\section{Carlota FERNÁNDEZ-JÁUREGUI ROJAS \\ María Jesús ZAMORA CALVO}

\begin{abstract}
Sin duda llegará un tiempo en que el labrador, trabajando sobre aquellos campos la tierra con el corvo arado, hallará las armas carcomidas por la herrumbre áspera, o con los pesados rastros golpeará cascos vacíos y contemplará, admirado, sobre las abiertas tumbas gigantescas osamentas.

Virgilio, Geórgicas, I, vv. 493-497

Trad. de Tomás de la Ascensión Recio García y Arturo Soler Ruiz
\end{abstract}

\begin{abstract}
S
i la palabra de un poeta es a veces materia suficiente para poder determinar el curso y destino de la vida de una persona, esto es algo que en nuestro caso puede afirmarse sin reservas de la obra poética de Antonio Gamoneda. Advertimos al lector que la completa y absorta dedicación
\end{abstract} a la lectura de su poesía supone la peligrosa entrada en una materia verbal y una espesura luminosa de las que uno después difícilmente puede desprenderse.

Desde el momento en que leyéramos por vez primera su obra -al que se sucedieron encuentros inolvidables con el poeta, con María Ángeles y con Amelia- hasta el presente, en que leemos sus poemas con la gratitud de quien recibe un bien preciado y reconoce por el tacto la geografía de un cuerpo poético que se ha amado y se sigue amando, no ha habido una palabra que no fuera impulsada por la suya, ni un momento que no esté de uno u otro modo relacionado con la poesía, con la voz y la figura de Antonio Gamoneda. Sus versos son «hierba cuyos hilos entran al corazón lleno de sombra, / líquenes en el residuo del amor».

Este libro es fruto de uno de los momentos que se anclan en ese proceso amoroso de conocimiento poético - un conocimiento que es siempre un «no saber», como dice Antonio Gamoneda en sus palabras preliminares-y reúne los textos de prácticamente todas las conferencias que, dedicadas a su poesía, se impartieron durante el Congreso «Poesía y Divergencia VII. Antonio Gamoneda (La Palabra Dañada)», realizado bajo la organización del profesor Rafael Morales Barba y celebrado entre la Universidad Autónoma de Madrid y la Biblioteca Nacional de España durante los días 15 al 17 de abril de 2009. Desde aquellos días de abril de 2009, hasta estos de junio de 2014, y gracias a la gentileza de Tropelías. Revista de Teoría de la Literatura y Literatura Comparada y en particular a la amabilidad de Túa Blesa, hemos podido finalmente reunir y editar los textos que aquí se entregan. 
El libro está dividido en dos secciones diferenciadas: por un lado, se encuentran los «Ensayos» de los distintos filólogos, estudiosos de la literatura y de la teoría literaria que participaron en el Congreso y, por otro lado, las «Lecturas» que varios poetas dedicaron, a través de sus propios versos, a los de Antonio Gamoneda. La primera sección queda inaugurada con el valioso ensayo de Tomás Albaladejo, «Inflexiones discursivas en la poesía de Antonio Gamoneda», que se detiene en las articulaciones, roturas y despedazamientos sintagmáticos de los poemas, encontrando en la figura del pensamiento de la sustentatio y en las interrogaciones retórico-poéticas, una fructífera vía para el estudio de la obra del poeta. Otras perspectivas de calado -y sin poder aquí aludir a cada una de las contribuciones que serían dignas de mención- son las de Antonio Méndez Rubio, quien en «Luz, cuerpo, trauma» nos ofrece una serie de pasajes sobre los elementos de desaparición y muerte, la de José Luis Gómez Toré sobre la animalidad gamonediana, en «El animal del llanto: bestiarios de la imaginación en la poesía de Antonio Gamoneda», o la de Fernando R. de la Flor quien, tanto en su ensayo «Antonio Gamoneda: divergencia de la actualidad; desinstalación en el presente» como en el estudio preliminar que realizara con Amelia Gamoneda en la antología de Sílabas negras, muestra un amplio conocimiento de la obra del poeta y de la relación de anomalía o divergencia que existe entre esta y su época. Por último, nos gustaría destacar la contribución de Antonio García Berrio, «Sobre la causa impulsiva en la inspiración de Gamoneda», por la imponente e imprescindible labor teóricoliteraria de toda una vida, que sigue continuándose en el presente.

Este libro es una pequeña muestra de nuestro inmenso reconocimiento a su obra, pero no encontrará aquí el lector palabras que puedan igualar o estar suficientemente a la altura de las suyas, porque la voz de Antonio Gamoneda avanza como un rumor que viene de lejos y se extiende; su poesía viene, como le llegan a uno los recuerdos que son presentimiento táctil, resonancia sensible, «intuición exacta» de algún lugar íntimo a nuestra conciencia. Se trata de una puesta ante el abismo, como la de aquella última flor de Cecilia que atraviesa la lengua por el lugar de su desaparición, cruzando por el cielo de la boca y del olvido, como lo hacen, al aire de su vuelo, en sus versos las palomas. Tocada por su palabra, la visión se despereza en imaginación, y pasa de la página a la memoria, guiada y poseída por cierto espíritu animal que entra primero por los ojos y se queda para siempre en el corazón: Antonio Gamoneda ha puesto definitivamente -y por decirlo con un verso de Descripción de la mentira- sus días en nuestros ojos. 